\title{
Evil and the god of indifference
}

\author{
László Bernáth ${ }^{1} \cdot$ Daniel Kodaj ${ }^{1}$
}

Received: 25 July 2019/Accepted: 25 February 2020 / Published online: 13 March 2020

(C) The Author(s) 2020

\begin{abstract}
The evidential problem of evil involves a rarely discussed challenge, namely the challenge of defending theism against the hypothesis of a morally indifferent creator. Our argument uses a Bayesian framework and it starts by showing that if the only alternative to classical theism is naturalistic atheism, then fine-tuning can render theism virtually certain, even in the face of evil. But if the alternatives include the hypothesis of a morally indifferent creator, theism is defeated even if the fine-tuning premise is accepted. The resulting version of the evidential problem is unsolvable using the tools that are currently deployed by theists against evil.
\end{abstract}

Keywords Alternative theologies · Bayesianism · Problem of evil

We will use Bayesianism to model the debate over the evidential significance of evil. A Bayesian solution to the problem of evil (BSPE) is an argument that has the following conclusion:

(B) $\quad P($ Theism $\mid$ Evil \& $R$ ) is significantly high

where $R$ is the rest of our evidence.

It is important to note that a BSPE may not amount to a defence or a theodicy. A theodicy purports to explain God's actual reasons for permitting evil, whereas a defence tells a story that, for all we know, could be true, and would, if true, explain why God permits evil. But a BSPE need not do either of those things, because (B) can hold even if it is subjectively quite improbable that God would permit evil.

Our starting point will be a BSPE that has the following premises:

(P1) The a priori probability of theism may be quite low but it is not spectacularly low

(P2) The subjective probability of God's permitting evil is quite low but it is not spectacularly low

Daniel Kodaj

dkodaj@gmail.com

1 Institute of Philosophy, Eötvös Loránd University, Budapest, Hungary 
(P3) The subjective probability of fine-tuning conditional on atheism is spectacularly low

(P4) Either classical theism (Judaeo-Christian-Muslim monotheism) or naturalistic atheism is true

(P5) Our total evidence regarding the truth or falsity of theism consists of evil plus the fact that the universe is fine-tuned for life

In the next section, we show that these premises ground a successful BSPE. In "Enter Moloch", we show if one relaxes (P4) by recognizing alternative theologies (specifically, by recognizing the possibility of a morally indifferent creator), then the Bayesian case for classical theism flounders. Finally, we examine potential ways to resist one specific indifferent-creator scenario. We argue that extant theistic strategies for dealing with the evidential problem fail and theism is defeated.

Our central claim is that the evidential problem of evil has a neglected aspect that can be studied through a Bayesian lens. The evidential problem of evil is in fact (at least) two different problems, the problem of defending theism against naturalistic atheism and the problem of defending theism against certain alternative theologies, for example, against the hypothesis of a morally indifferent creator. The latter controversy turns on a priori issues that seem to lack convincing theistic solutions.

Throughout the paper, we presuppose that Bayesianism is the right logic of abduction. This presupposition may sound controversial. There are well-known complaints against Bayesianism-for example, one can question the very notion of subjective probabilities (Horgan 2017), or one can reject the principle that subjective probability ought to be maximized (Buchak 2014). The paper is long enough as it is, so we won't address these points. Nor will we make a plea for Bayesianism specifically within the philosophy of religion. We are content to point to pioneering works in this area, such as Dougherty and McBrayer (2014) and Swinburne (2004). Those who are inclined to resist our argument solely on the grounds that it uses Bayesian methods are very welcome to suggest a better system of abductive logic.

\section{If (P1)-(P5) are true, then (B) is true}

Suppose that our evidence regarding the truth or falsity theism is exhausted by the following propositions:

NE There is natural evil (evil brought about by the lawlike operation of natural causes) in the amount, variety, and distribution as we actually find it

$M E \quad$ There is moral evil (evil brought about by the free actions of human beings) in the amount, variety, and distribution as we actually find it

Evil $M E \& N E$

Tuning Physical constants are fine-tuned in a way that the existence of life is physically possible 
To pin some numbers on the vague terms we used, we propose to cash out "quite low but not spectacularly low" as 1 percent and "spectacularly low" as $10^{-50}$, so that $(\mathrm{P} 1)-(\mathrm{P} 3)$ give rise to the following precise premises:

(1) $P($ Theism $) \geq 0.01$

(2) $P($ Evil $\mid$ Theism $)=0.01$

(3) $\quad$ (Tuning $\mid$ Atheism $)=10^{-50}$

We also need the following inequality, which will be justified in a moment:

$P($ Tuning | Theism \& Evil $) \geq 0.01$

Using the odds form of Bayes' theorem, (1)-(4) entail that theism is overwhelmingly more probable than atheism:

$$
\begin{aligned}
\frac{P(\text { Theism } \mid \text { Evil \& Tuning })}{P(\text { Atheism } \mid \text { Evil \& Tuning })} & =\frac{P(\text { Evil \& Tuning } \mid \text { Theism }) \cdot P(\text { Theism })}{P(\text { Evil \& Tuning } \mid \text { Atheism }) \cdot P(\text { Atheism })} \\
& =\frac{P(\text { Evil } \mid \text { Theism }) \cdot P(\text { Tuning } \mid \text { Theism \& Evil }) \cdot P(\text { Theism })}{P(\text { Tuning } \mid \text { Atheism }) \cdot P(\text { Evil } \mid \text { Atheism \& Tuning }) \cdot P(\text { Atheism })} \\
& \geq \frac{0.01 \cdot 0.01 \cdot 0.01}{10^{-50} \cdot 1 \cdot 0.99} \approx 10^{44}
\end{aligned}
$$

(See the "Appendix" for details.)

If theism and atheism are the only hypotheses under consideration, as (P4) says, so that their respective probabilities add up to 1 , then by (5), the posterior probability of theism is more than $99.9999999999 \%$ while the posterior probability of atheism is less than $0.0000000001 \%$. So (P1)-(P5) ground a rather successful BSPE if the way we quantified probabilities in (1)-(3) is defensible and if (4) is true. We'll cover the last two issues before explaining what we take to be the substantive message of this whole exercise.

We proposed to cash out "quite low but not spectacularly low" as having a subjective probability of 1 percent and "spectacularly low" as having a subjective probability of $10^{-50}$. These numbers are admittedly arbitrary to some extent. What matters, as far as the present dialectic is concerned, is that probabilities that are low but not spectacularly low are many orders of magnitude higher than spectacularly low ones and only a few orders of magnitude lower than 1. As long as this criterion is satisfied, the argument goes through. (The number at the end of (5) will be on the order of $10^{M A N Y-2 \times F E W}$, making the BSPE successful). What matters is not the choice of numerical values but the set of underlying qualitative claims, namely (P1), (P2), and (P3).

Lemma (4) needs justification before we move on. In terms of the estimates we introduced, (4) is tantamount to saying that the probability of fine-tuning, conditional on God and evil, may be quite low but it is not spectacularly low. This claim is supported by two thoughts. The first is that the universe is likely to be law-governed if God permits moral evil, because free action is impossible if agents cannot make reasonably good predictions about the consequences of their actions (Swinburne 1998: ch. 10). Further, if God creates a law-governed universe that contains moral evil, he is not spectacularly unlikely to institute laws that are fine- 
tuned for life, because fine-tuning may have providential significance. For example, it can supply creatures in an evil-infested world with grounds for thinking that God exists. ${ }^{1}$

Turning away from the formal details, we'd like to offer a story to illustrate the epistemic situation that the theist is in, according to our BSPE.

Clifftown was built on a plateau in an extremely high and precarious mountain range. There is only one way to approach Clifftown, and the road is so dangerous that travellers can't even take backpacks. (We're assuming that flight is technologically impossible when the story takes place.) The townspeople must work with the materials available nearby. Luckily, one of them, the Inventor, was a very resourceful craftsman who constructed simple machines from iron and various other stuff found in local mines. No other inhabitant of Clifftown has a talent for engineering and, obviously, no machine can be smuggled in from outside.

Everyone in Clifftown knows that the Inventor hates bronze. She wouldn't make anything out of bronze even if people begged her. This quirk does not trouble the townsfolk, however. The reason they are worried is that the Inventor seems to have disappeared. She hasn't created anything lately and nobody saw her in years. Although they hope that the Inventor returns, the inhabitants of Clifftown are more inclined to think that she is dead.

One day, one of the townsmen, Bob, spots a shiny new bronze bicycle in the streets of Clifftown. He finds this utterly perplexing. The Inventor did make bicycles in the past, but it seems quite improbable that anyone could have convinced her to make one out of bronze. On the other hand, the probability that someone else made the bike, or that the bike was miraculously transported here from outside, or that the wind assembled it by chance, is spectacularly low. So Bob forms the belief that the Inventor has been in town and she made a new bicycle, overcoming her fabled disgust of bronze.

Bob's posterior credences are rational. His evidence is quite improbable on the hypothesis that the Inventor created the bike, but his evidence is spectacularly improbable under the alternative hypothesis.

The structure of this story maps onto the structure of our BSPE. The hypothesis that the Inventor made the bicycle is analogous to Theism, the negation of this hypothesis is analogous to Atheism. The fact that the bike is made of bronze corresponds to evil and the fact that the bike is a machine corresponds to finetuning. Lemma (4) has no obvious analogue in the story, but it can be replaced by an assumption that does the same technical work. ${ }^{2}$

The substantive message of our BSPE is that theism is justified for roughly the same reasons that Bob's belief in the Inventor's presence is justified. Even though

\footnotetext{
${ }^{1}$ Halvorson (2018) objects to the fine-tuning argument on the grounds that God might be much more inclined to create laws that need no fine-tuning, and so fine-tuning may not be evidence for theism. Our lemma (4) is compatible with this contention. All we require is that God, once he permits moral evil, is not spectacularly unlikely to fine-tune the laws.

2 The probability of something's being a machine, conditional on its being bronze and having been made by Inventor, should not be too low. This is to be expected on the grounds that the Inventor builds machines out of metal.
} 
evil constitutes strong evidence against God, fine-tuning is so much stronger evidence against atheism that theists are perfectly rational to choose theism. More precisely, this is how our BSPE plays out if the premises are true.

One of the disanalogies between theism and the Clifftown case foreshadows the main challenge that our BSPE will face later. The hypothesis that someone other than the Inventor made the bicycle has a spectacularly low probability in the Clifftown case, because that's how the thought experiment was constructed. But it is far from clear that the analogous hypothesis in the debate over theism-the hypothesis that a supernatural being other than the God of classical theism created the universe-is spectacularly improbable. In the rest of the paper, we will study this specific challenge.

Finally, we'd like to point out that the BSPE we presented is not new. It is adumbrated by Hawthorne and Isaacs (2018: n44) as well as by Collins (2009: 256). But we believe that it is buried deep enough in the literature to make a detailed exposition helpful and relevant. Everyone working on the problem of evil should be aware that the improbability of atheistic fine-tuning can easily outbalance the evidential impact of evil. Ever since Rowe's (1979) paper, the philosophical controversy over evil has been dominated by the thought that evil constitutes extremely weighty evidence against theism. The BSPE that Collins and others have alluded to and that we explored above shows that Rowe's point is at least questionable as long as the only alternative to theism is naturalistic atheism. As we'll see, however, Rowe is right if nonstandard theologies come into play.

\section{Enter Moloch}

Our goal is to dismantle the BSPE we outlined. Specifically, we'll argue that relaxing (P4) — admitting morally indifferent deities_-wrecks the Bayesian case for theism. We take this to indicate that the evidential problem of evil has a neglected aspect that lacks a convincing theistic solution. As we will see, this claim can be justified independently of the BSPE in question, but (P1)-(P5) helps one see how the two aspects of the evidential problem come apart.

In the rest of the paper, we use "god" in a very wide sense to denote any supernatural entity or collective or phenomenon that can create a physical universe, or can manifest as a physical universe, or can give rise to physical reality in some other way, as long as it does so freely, without being externally compelled. Cosmic teleology qualifies as a god on the present terminology. So do various communities of polytheistic gods.

To simplify the discussion, we will focus on one specific alternative theology:

The Moloch Hypothesis

Moloch is an omnipotent being who isn't morally good in our sense of "good". His desire is to create a universe that exemplifies a huge variety of aesthetic qualities (beauty, majesty, tragedy, comedy, repulsiveness, absurdity etc.). As a result, Moloch is quite interested in various forms of evil. For the same reason, he is very interested in life. He is also interested in quasars, 
comets, wars, continental drift, symbolic poetry, and a host of other things familiar from the actual world. Being a sort of cosmic aesthete, Moloch is almost certain to create a physical universe, and if he does so, he is very likely to create one that is similar to the actual world. (He may create a host of other universes to observe the multitude of ways beauty and ugliness can develop, but given the richness of the actual world, he is bound to create one that looks like it.)

Suppose that the existence of Moloch is just as probable a priori as the existence of the classical God and that he is exactly as likely to create a fine-tuned universe. By assumption, evil has a very high probability conditional on Moloch, say .95 . Using the odds form of Bayes's theorem, we have that

$$
\begin{aligned}
& \frac{P(\text { Theism } \mid \text { Evil \& Tuning })}{P(\text { Moloch } \mid \text { Evil \& Tuning })}=\frac{P(\text { Evil \& Tuning } \mid \text { Theism }) \cdot P(\text { Theism })}{(\text { Evil \& Tuning } \mid \text { Moloch }) \cdot P(\text { Moloch })} \\
& =\frac{P(\text { Evil } \mid \text { Theism }) \cdot P(\text { Tuning } \mid \text { Theism \& Evil }) \cdot P(\text { Theism })}{P(\text { Evil } \mid \text { Moloch }) \cdot P(\text { Tuning } \mid \text { Moloch \& Evil }) \cdot P(\text { Moloch })}=\frac{0.01}{0.95} \approx 0.01
\end{aligned}
$$

By (6), classical theism is much less probable than the Moloch Hypothesis. So the Bayesian agent is bound the discard the former if the latter is an admissible alternative.

This conclusion persists even if (P5) is denied, in other words, even if one admits evidence beyond evil and fine-tuning. To see why, consider that

(7) $\frac{P(\text { Theism } \mid \text { All evidence })}{P(\text { Moloch } \mid \text { All evidence })}=\frac{P(\text { All evidence } \mid \text { Theism })}{P(\text { All evidence } \mid \text { Moloch })} \cdot \frac{P(\text { Theism })}{P(\text { Moloch })}$

If this ratio heavily favours the Moloch hypothesis, the Bayesian reasoner will take classical theism to be false. Whether he will take the Moloch hypothesis to be true depends on the range of relevant alternatives. For example, if naturalistic atheism, classical theism, and the Moloch Hypothesis are the only contenders, Moloch will win (if the fine-tuning premise, (P3), holds). But some other form of supernaturalism may beat even Moloch. What matters is that the game is over for classical theism if (7) is much lower than 1.

Now the nominator of (7) cannot be greater than $P($ Evil | Theism), since the nominator can be decomposed into a product of probabilities that include $P($ Evil | Theism) (see "Appendix"):

$$
\begin{aligned}
& P(\text { All evidence } \mid \text { Theism }) \cdot P(\text { Theism }) \\
& \quad=P(\text { Evil } \mid \text { Theism }) \cdot P(\text { All other evidence } \mid \text { Theism \& Evil }) \cdot P(\text { Theism })
\end{aligned}
$$

The last two terms in (8) are at most 1, so the whole expression cannot be greater than $P($ Evil । Theism $)$. Suppose that the latter, as per $(\mathrm{P} 2)$, is low but not spectacularly low. Let's estimate it at 1 percent.

Assuming that the priors of Theism and Moloch are equal, it follows that

(9) $\quad \frac{P(\text { Theism } \mid \text { All evidence })}{P(\text { Moloch } \mid \text { All evidence })} \leq \frac{0.01}{P(\text { All evidence } \mid \text { Moloch })}$ 
Suppose, for illustration, that the probability of our total evidence conditional on Moloch is high. Say it's .95. Then by (9), the Moloch Hypothesis is at least 95 times more likely, all things considered, than theism. Generally, theism is guaranteed to lose out to Moloch if Moloch is not quite unlikely a priori and if $P($ All evidence | Moloch) is not low.

It is safe to say that $P($ All evidence $\mid$ Moloch $)$ is not low. Even if our evidence base includes mystical experience, pleasure, alleged miracles, alleged revelation, the facts of religious diversity etc., it is hard to find anything in the resulting package that would be unlikely if Moloch existed, and we see no reason to think that the package as a whole would be unlikely if Moloch existed. To the contrary, it seems to us that the kind of world we're living in has a very high subjective probability of existing if the Moloch Hypothesis true, in other words, it seems to us that $P($ All evidence $\mid$ Moloch $)$ is quite high.

Note, further, that the Moloch hypothesis is unaffected by the kind of evidence that could vindicate theism in the debate against naturalistic atheism. Imagine that we have grounds for thinking that Jesus was resurrected. This piece of evidence won't make the numerator of (9) greater, because the numerator cannot be greater than the probability of evil under theism, which is quite low. On the other hand, the resurrection of Jesus won't make the denominator of (9) any lower, because Jesus could very well have been resurrected by Moloch. Perhaps Moloch is amused by a cult that is born out of a cosmic misunderstanding but takes over a giant empire, spreads all over the world, and transforms its followers in all sorts of surprising ways.

In order to portray the resurrection of Jesus as evidence that is very unlikely under the Moloch Hypothesis, one would have to claim that something like (10) is part of our evidence base:

(10) Jesus was resurrected by the God of Abraham, Isaac, and Jacob

But this kind evidence is hard to get. Indeed, if such evidence were available, one could conclude right away that classical theism is true.

An interlocutor could reply that (10) counts as evidence if Plantinga (2000) is right and theistic beliefs constitute knowledge whenever the believer's sensus divinitatis is working reliably in an appropriate environment. On such a view, theists know that the Resurrection occurred, and, assuming that knowledge is evidence, propositions like (10) are parts of their evidence base.

Unfortunately, the belief-forming mechanisms that supposedly generate such knowledge can only generate that knowledge if theism is true. If all religions were created by Moloch, then Abrahamic testimony is unreliable, along with our sensus divinitatis (or perhaps the latter is working in an unfavourable environment). So even if (10) could in principle be a piece of knowledge, whether (10) is a piece of knowledge is not known to the Bayesian reasoner. ${ }^{3}$

\footnotetext{
3 More technically, the Bayesian reasoner needs evidence that (10) is evidence. As far as we can see, only some independent evidence for theism will do. See Baker-Hytch (2018) for a closely related worry about treating religious testimony as evidence.
} 
Similar remarks apply to religious experience. Just as the resurrection of Jesus can be explained by the Moloch Hypothesis, so can religious experience. Friends of Moloch agree that religious experience is evidence for the existence of a deity, but they deny that the deity in question fits the classical theistic conception. The eternal bliss that mystics partake of is the bliss of Moloch.

The theist could suggest that her theory offers a better explanation for resurrection, religious experience (etc.), than the Moloch Hypothesis. But this objection is worth less in Bayesian terms than it may seem, because theism is not a very good explanation of evil, whereas the Moloch Hypothesis is. The theist needs some fact that tells as strongly against Moloch as evil does against the God of classical theism, and no such facts are apparent.

Even worse, extant theistic strategies against the evidential problem of evil are useless against Moloch. Defenses and theodicies, interpreted in Bayesian terms, seek to prevent $P($ Evil $\mid$ Theism $)$ from being very low; at the very best, they push it toward .5. That still leaves theism considerably less probable than Moloch if $P(A l l$ evidence (Moloch) is high, which, as we saw, is highly defensible. And even if the theist claims that God wants there to be evil, the best she can achieve (at the cost of saying something incredible) is parity with the Moloch Hypothesis. So the Moloch Hypothesis represents a serious challenge even if the theist is willing to buy into highly tenuous theories.

Sceptical theism is likewise powerless against Moloch. Sceptical theists believe that we are cognitively ill-equipped to asses whether evil is strong evidence against theism. In the present context, this idea seems to be ineffective. The most that the sceptical theist can achieve is to estimate $\mathrm{P}($ Evil । Theism) at .5 (representing absolute uncertainty or complete lack of knowledge). But that is not enough in the present context. Unless some other part of our evidence base is less than .5 likely under Moloch (which seems not to be the case), Moloch beats classical theism even if the Bayesian reasoner buys into sceptical theism.

Finally, notice that this reasoning does not turn on the trivial fact that for any theory $T$ and evidence $E$ such that $P(T \mid E)<0$, one can find a theory $T$ such that $P\left(T^{\prime} \mid E\right)=1$. (Just add $E$ as an exception clause to $T$.) The Moloch Hypothesis is not a gerrymandered, ad hoc mathematical artefact. Indeed, there are perfectly reasonable ways to motivate it. Suppose one accepts that fine-tuning is strong evidence for a creator and one also believes, quite strongly, that bone cancer in children, genocide, mass rape etc. are strong evidence against a morally good creator. Together, these two convictions lead naturally to the idea of a morally indifferent creator. The hypothesis of a morally indifferent creator explains both types of evidence, order and evil. So the Moloch Hypothesis, which is just one specific version of the indifferent-creator theory, is far from being a mere mathematical artefact.

Nor are such theories mere dialectical gimmicks. Aristotle's prime mover, Plotinos's One, and Spinoza's substance are sufficiently similar to Moloch to qualify as significantly more probable on Bayesian grounds, along the lines of (9), than the God of classical theism. As far as we know, nobody objected to these conceptions on the grounds that they are ad hoc. 


\section{Resisting Moloch a priori}

Classical theism loses out to Moloch if the latter is a priori just as probable as the former. Conversely, if the Moloch hypothesis is improbable a priori, it ceases to constitute a genuine challenge, as indicated by (7):

(7) $\frac{P(\text { Theism } \mid \text { All evidence })}{P(\text { Moloch } \mid \text { All evidence })}=\frac{P(\text { All evidence } \mid \text { Theism })}{P(\text { All evidence } \mid \text { Moloch })} \cdot \frac{P(\text { Theism })}{P(\text { Moloch })}$

If $P($ Moloch $)$ can be shown to be so low that it offsets the contribution of evil to the numerator, then theism prevails. Indeed, this seems to be the only strategy available to the theist. She needs to show that Moloch is a priori significantly less probable than the Abrahamic God.

It is very easy to render $P($ Moloch $)$ extremely low: adopt subjective Bayesianism. According to subjective Bayesians, the distribution of priors is a game without any rules beyond mathematical consistency. Your priors depend on nothing but your preexisting beliefs or intuitions. ${ }^{4}$ On subjective Bayesian grounds, the problem of Moloch is trivial to solve.

Subjective Bayesianism offers a similarly easy solution to the standard problem of evil: set $P$ (Atheism) fantastically low and you're done. This fact indicates that subjective Bayesianism is unable to model the dialectical situation in the philosophy of religion. Arbitrary intuitions about priors seem inappropriate in that context. A more reasonable principle is that the priors obey certain constraints: a priori probabilities are fixed (within vague but not too wide limits) by a priori knowledge. ${ }^{5}$

We are not aware of commonly accepted a priori truths that the theist could deploy against Moloch, so we believe that theists have a problem here. At best, they have to explain how their preexisting a priori knowledge renders Moloch improbable. At worst, they must acknowledge a new, potentially unsolvable version of the evidential problem of evil.

To round off the discussion, we'll consider one specific a priori strategy against Moloch, the suggestion that moral perfection is a consequence of some of the attributes that creator gods are supposed to have. For example, following Swinburne (2004: 99-106), the theist could argue that omniscience entails moral perfection, because an all-knowing being knows all moral truths, and moral truths, in turn, are intrinsically motivating. Or, following Zagzebski (1997: 306), the theist could claim that omniscience entails compassion. Or, focusing specifically to Moloch, the theist could suggest that being a cosmic aesthete entails an appreciation of, and desire for, moral goodness. ${ }^{6}$

We believe that arguments in this vicinity rest on two questionable premises. The first is that there is a metaphysically necessary connection between being motivated to be good and some supernatural trait (for example, omnisicence, or being a cosmic aesthete). We don't think that such alleged entailments constitute a priori knowledge. Amoral omniscient beings and amoral cosmic aesthetes seem perfectly conceivable.

\footnotetext{
${ }^{4}$ De Finetti (1980). For opposition, see Williamson (2010) and Williamson (2000: ch. 9).

5 See Horwich (1982: 70f) for more on this principle.

${ }^{6}$ We thank an anonymous referee for these suggestions.
} 
Second, these arguments presuppose moral realism, more specifically, they presuppose that human well-being is objectively valuable. But this sort of humancentric moral realism is not a piece of a priori knowledge either. As one friend of morally indifferent deities put it:

After men persuaded themselves that everything which happens, happens on their account, they had to judge that what is most important in each thing is what is most useful to them, and to rate as most excellent all those things by which they were most pleased. Hence, they had to form these notions, by which they explained natural things: good, evil, order, confusion, warm, cold, beauty, ugliness. [...] [A]ll the notions by which ordinary people are accustomed to explain Nature are only modes of imagining, and do not indicate the nature of anything, only the constitution of the imagination. [...] $[\mathrm{T}]$ he perfection of things is to be judged solely from their nature and power; things are not more or less perfect because they please or offend men's senses, or because they are of use to, or are incompatible with, human nature. (Spinoza: Ethics, part I appendix, 1994: 113-115)

We are not advocating Spinozism. We claim that it is not known to be false. And so its negation cannot be used to make $P($ Moloch $)$ low.

An interlocutor could suggest that something less than knowledge is enough here: a reasonable level of a priori certainty will do. If the theist thinks that human wellbeing is objectively valuable and if she is certain that being omniscient (or being a cosmic aesthete) entails recognizing its value, then she has a good a priori case against Moloch.

To asses this response, we'll focus on one specific a priori strategy against Moloch, the one inspired by Swinburne. This strategy rests on two basic claims:

(H) Human-centric moral realism is true (human well-being is objectively valuable)

(M) Moral truths are intrinsically motivating (moral judgments result in moral motivation)

According to the interlocutor, it is sufficient for the theist to be reasonably certain that these propositions are true. It is not required that these propositions constitute a priori knowledge. ${ }^{7}$

The interlocutor's suggestion adds another layer of complexity to the debate. In Bayesian terms, the interlocutor recommends extending the Bayesian calculus to potential a priori evidence, specifically, to $\mathrm{H}$ and $\mathrm{M}$.

Suppose that such an extension makes sense. Then the a priori probability of Moloch can be decomposed in the following way:

$$
\begin{aligned}
& P(\text { Moloch })=P(\text { Moloch } \mid H \& M) \cdot P(H \& M)+P(\text { Moloch } \mid \sim H \vee \sim M) \\
& P(\sim H \vee \sim M)
\end{aligned}
$$

\footnotetext{
7 Note that theists who use this strategy cannot subscribe to Divine Command Theory to secure moral realism, on pain of making their case against Moloch question-begging.
} 
To simplify, suppose that Moloch is by definition omniscient and therefore $P($ Moloch $\mid \mathrm{H} \& \mathrm{M})$ is 0 . And let's estimate $P($ Moloch $\mid \sim H \vee \sim M)$ at 0.5 , on the grounds that $(\sim H \vee \sim M)$ by itself does not either support or weaken the Moloch Hypothesis.

One can decompose the prior of theism in a similar way:

$$
P(\text { Theism })=P(\text { Theism } \mid \mathrm{H} \& \mathrm{M}) \cdot P(\mathrm{H} \& \mathrm{M})+P(\text { Theism } \mid \sim \mathrm{H} \vee \sim \mathrm{M}) \cdot P(\sim \mathrm{H} \vee \sim \mathrm{M})
$$

We want to be generous to the theist, so we estimate $P$ (Theism $\mid \mathrm{H} \& \mathrm{M}$ ) at 1 , assuming that moral realism entails theism. (It probably does not, of course, but never mind.) And we will estimate $P($ Theism $\mathrm{I} \sim \mathrm{H} \vee \sim \mathrm{M})$ at $0.5 .^{8}$ Again, this point may be contested, since the falsity of $\mathrm{H}$ alone is pretty likely to render theism false. But we're trying to be generous to the theist.

Putting (11) and (12) together and using the estimates, we have that

$$
\frac{P(\text { Theism })}{P(\text { Moloch })}=\frac{1 \cdot P(\mathrm{H} \& \mathrm{M})+0.5 \cdot P(\sim \mathrm{H} \vee \sim \mathrm{M})}{0.5 \cdot P(\sim \mathrm{H} \vee \sim \mathrm{M})}=\frac{2 \cdot P(\mathrm{H} \& \mathrm{M})}{P(\sim \mathrm{H} \vee \sim \mathrm{M})}+1
$$

Using tricks discussed under (8) and (9), one can estimate the ratio of $P($ A posteriori evidence | Theism) and $P($ A posteriori evidence I Moloch) to be approximately equal to $P($ Evil $\mid$ Theism $)$. For illustrative purposes, take the latter to be .01. Then by (7) and (13), it follows that theism is more probable than Moloch, all things considered, if the following inequality holds:

$$
\frac{P(\mathrm{H} \& \mathbf{M})}{P(\sim \mathrm{H} \vee \sim \mathrm{M})}>\frac{1}{0.02}-0.5
$$

Since the right-hand side is 49.5 , this inequality says, in essence, that $\mathrm{H} \& \mathrm{M}$ is overwhelmingly more likely a priori than its negation.

We don't see how the theist can secure (14) by appealing to commonly accepted constraints on the relevant priors. In order to portray $\mathrm{H} \& \mathrm{M}$ as overwhelmingly more likely a priori than its negation, the theist should produce knock-down arguments for two extremely weighty philosophical principles, namely a form of moral realism $(=\mathrm{H})$ and anti-Humeanism about moral motivation $(=\mathrm{M}) .{ }^{9}$ No knock-down arguments exist for these theories. Generally, the a priori probability of controversial philosophical theories can't be significantly higher than .5. Using .6 as a conservative estimate and assuming that $\mathrm{H}$ and $\mathrm{M}$ are independent, the left-hand side of (14) is at most $0.56(=0.36 / 0.64)$. So (14) is guaranteed to be false.

More simply, consider that (14) is false if one of $\sim \mathrm{H}$ and $\sim \mathrm{M}$ fails to be considerably unlikely a priori. Since morally imperfect omniscient beings are prima

\footnotetext{
${ }^{8}$ If $P($ Theism $\mathrm{I} \sim \mathrm{H} \vee \sim \mathrm{M})=P($ Moloch $\mathrm{I} \sim \mathrm{H} \vee \sim \mathrm{M})=0.5$, then theism and Moloch are the only alternatives, assuming $(\sim \mathrm{H} \vee \sim \mathrm{M})$. This is unrealistic, but one can pretend that the probabilities are normalized within a subspace of the whole probability space.

9 Alternatively, the theist can give up $\mathrm{M}$ and accept Humeanism about moral motivation, assuming that moral motivation requires, in addition to moral judgment, a desire to follow the moral rules. To secure a link between being a god and being moral, the theist will then have to claim that being a god somehow entails the desire to be moral. This premise seems even less harder to secure than $\mathrm{M}$.
} 
facie positively conceivable, $\sim \mathrm{H}$ does not seem too unlikely a priori. So (14) seems to be false. And note that (14) itself is based on two implausible premises that help the theist, the premise that $P($ Theism $\mathrm{I} \sim \mathrm{H} \vee \sim \mathrm{M})$ is 0.5 and the premise that $P($ Theism $\mid \mathrm{H} \& \mathrm{M})$ is 1 . More realistic estimates will make it even harder for the theist to avoid defeat. For example, if $P($ Theism $\mid \mathrm{H} \& \mathrm{M})$ is .75 and $P($ Theism $\mathrm{I} \sim \mathrm{H} \vee \sim \mathrm{M}$ ) is .25, then by (7), (11), and (12), and leaving the rest of the earlier estimates in place, ${ }^{10}$ it follows that $P($ Evil $\mid$ Theism $)$ should be at least 0.744 in order for theism to avoid defeat. That's a tall order.

The Swinburnian strategy against Moloch fails the test of Bayesianism. Although we used specific quantitative estimates, we believe that the qualitative point is valid: in order for theism to prevail against Moloch, $(\sim \mathrm{H} \vee \sim \mathrm{M})$ should be at least as improbable (compared to its negation) as evil is under theism. ${ }^{11}$ Since both $\sim \mathrm{H}$ and $\sim$ M seem at least moderately probable, the Swinburnian strategy fails. Similar points could be raised against the other a priori anti-Moloch arguments that we mentioned earlier.

\section{Conclusion}

Evil presents an under-discussed challenge to the theist, the challenge of fending off morally indifferent gods. Such gods seem more likely a posteriori than the God of classical theism, and extant theistic tools for solving the evidential problem of evil do not work against them. It appears that theists can only solve the challenge of indifferent gods by portraying them as a priori relatively unlikely. We argued that one potential strategy—linking divine traits to moral perfection-fails on Bayesian grounds.

Although our dialectic focused on a specific Bayesian attempt to solve to the problem of evil, namely (P1)-(P5), we believe that our conclusion generalizes. The Bayesian case for Moloch and his ilk does not depend on the details of the argument we examined. We tried to illustrate that the evidential problem of evil has at least two aspects: an a posteriori one that concerns the challenge of naturalistic atheism, and an a priori one that concerns the challenge of morally indifferent gods.

Acknowledgements Open access funding provided by Eötvös Loránd University (ELTE). László Bernáth was supported by the János Bolyai Research Scholarship of the Hungarian Academy of Sciences (code: BO/00432/18/2), the ÚNKP-19-4 New National Excellence Program of the Ministry for Innovation and Technology (code: ÚNKP-19-4-ELTE-1202), OTKA (Hungarian Scientific Research Fund of the National Research Development and Innovation Office) grant no. K132911, K123839, and a Higher Education Institutional Excellence Grant at Eötvös Loránd University, Faculty of Humanities.

\footnotetext{
${ }^{10} P($ Moloch $\mid \sim \mathrm{H} \vee \sim \mathrm{M})=0.5, P($ Moloch $\mid \mathrm{H} \& \mathrm{M})=0, P(H \& M)=0.36$, and the first ratio on the right-hand side of (7) is equal to $P($ Evil $\mid$ Theism).

${ }^{11}$ If $P($ Theism $\mid \mathrm{H} \& \mathrm{M})$ is below 1 , the theist is even worse off, so that assumption does not affect our conclusion. The values of $P($ Theism $\mathrm{I} \sim \mathrm{H} \vee \sim \mathrm{M})$ and $P($ Moloch $\mathrm{I} \sim \mathrm{H} \vee \sim \mathrm{M})$ won't make much difference as long as the former is not dramatically higher than the latter and the latter is not too low.
} 
Open Access This article is licensed under a Creative Commons Attribution 4.0 International License, which permits use, sharing, adaptation, distribution and reproduction in any medium or format, as long as you give appropriate credit to the original author(s) and the source, provide a link to the Creative Commons licence, and indicate if changes were made. The images or other third party material in this article are included in the article's Creative Commons licence, unless indicated otherwise in a credit line to the material. If material is not included in the article's Creative Commons licence and your intended use is not permitted by statutory regulation or exceeds the permitted use, you will need to obtain permission directly from the copyright holder. To view a copy of this licence, visit http:// creativecommons.org/licenses/by/4.0/.

\section{Appendix}

The odds form of Bayes's theorem, used in (5), (6), and (7), relates the ratio of the probability of two hypotheses, conditional on our evidence, to the ratio of the evidence's probability, conditional on the hypotheses in question:

(I) $\frac{P(A \mid E)}{P(B \mid E)}=\frac{P(E \mid A) \cdot P(A)}{P(E \mid B) \cdot P(B)}$

This formula (like most Bayesian formulae) follows from the definition of conditional probability:

(II)

$$
P(A \mid E)=\frac{P(A \& E)}{P(E)}
$$

which entails that

$$
P(A \mid E)=P(E \mid A) \cdot \frac{P(A)}{P(E)}
$$

which, in turn, entails (I).

In the main text, (5), (6), and (8) use the following formula to decompose the probability of complex evidence $(E \& F)$ conditional on some hypothesis $A$ :

(IV) $P(E \& F \mid A)=P(E \mid A) \cdot P(F \mid A \& E)$

This theorem is also a direct consequence of (I):

(V) $P(E \& F \mid A)=\frac{P(A \& E \& F)}{P(A)}=\frac{P(A \& E)}{P(A)} \cdot \frac{P(A \& E \& F)}{P(A \& E)}$

\section{References}

Baker-Hytch, M. (2018). Testimony amidst diversity. In M. A. Benton, J. Hawthorne, \& D. Rabinowitz (Eds.), Knowledge, belief, and god: New insights in religious epistemology (pp. 184-203). Oxford: Oxford University Press.

Buchak, L. (2014). Belief, credence, and norms. Philosophical Studies, 169, 1-27.

Collins, R. (2009). The teleological argument. In W. L. Craig \& J. P. Moreland (Eds.), The Blackwell companion to natural theology (pp. 202-281). Oxford: Blackwell. 
de Finetti, B. (1980). Foresight: Its logical laws, its subjective sources. In H. E. Kyburg \& H. E. Smokler (Eds.), Studies in subjective probability (pp. 53-118). Malabar: Robert E. Kriegler Publishing Company.

Dougherty, T., \& McBrayer, J. P. (Eds.). (2014). Sceptical theism: New essays. Oxford: Oxford University Press.

Halvorson, H. (2018). A theological critique of the fine-tuning argument. In M. A. Benton, J. Hawthorne, \& D. Rabinowitz (Eds.), Knowledge, belief, and god: New insights in religious epistemology. Oxford: Oxford University Press.

Hawthorne, J., \& Yoaav, I. (2018). Fine-tuning fine-tuning. In M. A. Benton, J. Hawthorne, \& D. Rabinowitz (Eds.), Knowledge, belief, and god: New insights in religious epistemology (pp. 137-169). Oxford: Oxford University Press.

Horgan, T. (2017). Troubles for Bayesian formal epistemology. Res Philosophica, 94(2), 233-255.

Horwich, P. (1982). Probability and evidence. Cambridge: Cambridge University Press.

Plantinga, A. (2000). Warranted christian belief. Oxford: Oxford University Press.

Rowe, W. L. (1979). The problem of evil and some varieties of atheism. American Philosophical Quarterly, 16(4), 335-341.

Spinoza, B. (1994). Ethics. In E. Curley (Ed.), A spinoza reader (pp. 85-265). Princeton: Princeton University Press.

Swinburne, R. (1998). Providence and the problem of evil. Oxford: Clarendon Press.

Swinburne, R. (2004). The existence of god (2nd ed.). Oxford: Clarendon Press.

Williamson, T. (2000). Knowledge and its limits. Oxford: Oxford University Press.

Williamson, J. (2010). In defence of objective Bayesianism. Oxford: Oxford University Press.

Zagzebski, L. (1997). Perfect goodness and divine motivation theory. Midwest Studies in Philosophy, 21, 296-309.

Publisher's Note Springer Nature remains neutral with regard to jurisdictional claims in published maps and institutional affiliations. 